\title{
PUESTAS EN ESCENA DE OBRAS DE DRAMATURGAS EN LA CARTELERA DE $A B C$ DE MADRID (2006-2009)
}

\author{
STAGE PRODUCTION OF WOMEN PLAYWRIGHTS \\ IN THE BILLBOARD OF ABC MADRID (2006-2009)
}

\author{
Valentina TORRISI \\ Grupo de investigación del SELITEN@T \\ vk.torrisi@gmail.com
}

\begin{abstract}
Resumen: Este artículo es un comentario sobre las piezas de autoría femenina que se representaron en los teatros madrileños recogidos en la cartelera de $A B C$ de Madrid durante los años 2006-2009. El trabajo, inserto en las actividades del Centro de Investigación de Semiótica Literaria, Teatral y Nuevas Tecnologías (SELITEN@T), dirigido por el profesor José Romera Castillo, se centra en la presentación de las dramaturgas, tanto españolas como extranjeras, y de ${ }^{\circ}$ sus obras, con el objetivo de establecer los logros que han alcanzado dentro de la producción escénica contemporánea en la capital de España.
\end{abstract}

Palabras clave: Dramaturgas. Puestas en escena. Madrid. $A B C$ de Madrid. 2006-2009.

Abstract: This essay is a commentary on the plays written by women playwrights and performed at the theatres of Madrid in the Madrid ABC'S Billboard in 2006-2009. The work, included in the agenda of the Centro de Investigación de Semiótica Literaria, Teatral y Nuevas Tecnologías 
(SELITEN@T), led by professor José Romera Castillo, focuses on the presentation of Spanish and foreign women playwrights, and their work, with the aim of assessing the achievements they reached within the contemporary stage production of the Spanish capital.

Key Words: Women Playwrights. Staging. Madrid. $A B C$ Madrid. 20062009.

\section{INTRODUCCIÓN}

La aportación de las mujeres a la producción artístico-literariateatral ha sido desde siempre bastante escueta en comparación con la producción masculina, debido a causas históricas y sociales. De hecho, solo después de la muerte del general Franco y de la consolidación de la reforma democrática en España, se inicia una significativa transformación de su cartelera por lo que respecta a la presencia en sus escenarios de dramaturgias femeninas. Pensemos, por ejemplo, en la creación de la Asociación de Dramaturgas Españolas en 1987 y en su incorporación en la Asociación de Autoras y Autores de Teatro en 1990.

Como la bibliografía al respecto es muy amplia, solamente me fijaré en lo realizado en nuestro Centro de investigación, muy especialmente a lo referido al teatro. El profesor Romera Castillo ha realizado aportaciones valiosas al espacio de investigación que nos ocupa, no solo con sus estudios, sino también con la dirección del Centro de Investigación de Semiótica Literaria, Teatral y Nuevas Tecnologías (cuyas actividades pueden verse en http://www.uned.es/centro-investigacion-SELITEN@T [03/01/2018]).En el primer caso, remitimos, entre otros, a los siguientes trabajos: "Estudio de las dramaturgas en los Seminarios Internacionales del SELITEN@T y en la revista Signa. Una guía bibliográfica" (Romera Castillo, 2010); "Las dramaturgas en el SELITEN@T” (Romera Castillo, 2011a); “Las dramaturgas" (Romera Castillo, 2011b); “Algo más sobre dramaturgias 
femeninas en los inicios del siglo XXI" (Romera Castillo, 2014), etc.

En cuanto a la actividad del SELITEN@T —además del proyecto europeo Dramaturgae (llevado a cabo por el mencionado Centro, la Universidad de Toulouse y la de Giessen, cuyas actas se han editado) y la publicación de diversos artículos (en sus Seminarios internacionales y en su revista Signa: ver http://www2.uned.es/centro-investigacion-SELITEN@T/ publipres.html [03/01/2018] — remitimos, entre otros trabajos, a los de tres integrantes del grupo de investigación sobre nuestro tema: los de Annalisa Domenica Bonaccorsi (2017), Valeria Lo Porto (2012) y Anita Viola (2012a) sobre la cartelera en $A B C$ de Madrid, en los años 1980-1984, 1990 y 2000, respectivamente ${ }^{1}$. En esta misma línea de trabajo, guiada por nuestro maestro, se configura la presencia de las principales dramaturgias femeninas, tanto españolas como extranjeras, que, durante los años 2006-2009, se llevaron a la escena en los teatros madrileños, según se constata en la principal fuente documental utilizada: la cartelera de $A B C$ de Madrid. Después de una breve referencia a la vida de cada dramaturga, procederemos a indicar la fecha y el teatro donde se estrenó cada pieza, así como un pequeño resumen del argumento.

${ }^{1}$ Este trabajo se inserta dentro de las actividades del Centro de Investigación de Semiótica Literaria, Teatral y Nuevas Tecnologías, dirigido por el profesor José Romera Castillo. Añadiré que en el mencionado Centro, también bajo la dirección del Dr. Romera, se han defendido las siguientes tesis de doctorado, relacionadas con el teatro en Madrid: la de Valeria Lo Porto (2013), Cartelera teatral en ABC de Madrid (1990-1994); la de Anita Viola (2012b), Cartelera teatral en "ABC de Madrid" (2000-2004) y la de Annalisa Domenica Bonaccorsi (2016), Cartelera teatral en "ABC de Madrid" (1980-1984); además de varias memorias de Investigación y Trabajos Fin de Máster, que pueden leerse completos en http://www2.uned.es/centro-investigacion-SELITEN@T/estudios_sobre_ teatro.html [03/01/2018]. 


\section{DRAMATURGAS EN LENGUA ESPAÑOLA}

\subsection{España}

\subsubsection{Pilar Almansa, Mónica Sagrera y Lourdes León}

La madrileña Mónica Sagrera (1973-) $)^{2}$ y las cordobesas Pilar Almansa (1976-) $)^{3}$ y Lourdes León (1981-) $)^{4}$ son las autoras del drama Superficie: vestimos a la humanidad. Después de su estreno, en diciembre de 2005 en el Centro Cultural José de Espronceda de Madrid, el espectáculo se representó en la misma ciudad, el 12 de enero del 2006, en el teatro Victoria, y permaneció en cartel hasta el 28 de enero del mismo año. La pieza logró un total de 9 funciones. El reparto estuvo formado por Manuel Domínguez, Mercedes Hinojosa, Lourdes León, Alex López, Mónica Sagrera y Elisabeth Solá. El drama hace un paralelismo entre los regímenes totalitarios y unos grandes almacenes; en este mundo ficticio las mujeres y los hombres trabajan como piezas del engranaje de una máquina que no acepta errores e imperfecciones. La obra es el primer trabajo de Pilar Almansa como directora:

Fue un proceso durísimo, era mi primer trabajo como directora y dramaturga. La primera vez que te enfrentas a ello tienes que entender que todos los actores tienen más experiencia en su rol de intérprete que tú en tu rol de dirección, y por tanto generar dinámicas creativas de grupo puede resultar complicado (López Escuer, 2017).

\footnotetext{
${ }^{2}$ Mónica Sagrera es una actriz, presentadora y directora de teatro española. Estudió Arte Dramático en Teatro de Cámara y dirigió las siguientes obras: Viceversa (2013), Mi vida 2.0 (2012) у Ме muero porque te mueras (2011).

${ }^{3}$ Pilar Almansa es una dramaturga licenciada en Periodismo por la Universidad Complutense de Madrid y en Dirección de escena por la RESAD. Escribió Una pieza de género (2006), La madre que nos parió (2007) y La red contra la red (2009).

${ }^{4}$ Lourdes León es una de las cofundadoras de la compañía Ungrupo Producciones. Trabajó como actriz en Los náufragos (2006) y después formó su propia compañía, Miraclaun.
} 


\subsubsection{Inmaculada Alvear}

Inmaculada Alvear (1960-) es una ensayista, filóloga e investigadora madrileña. Por lo que se refiere a su actividad teatral, en el cuatrienio analizado se han representado dos obras: En un minuto (N1m) y Mi vida gira alrededor de 500 metros. La comedia En un minuto $(\mathrm{N} 1 \mathrm{~m})$ se estrenó el 14 de enero de 2009 en el Centro Párraga de Murcia, se escenificó el 30 de junio de 2009 en el Círculo de Bellas Artes de Madrid y se representó 5 veces, hasta el 4 de julio del mismo año. El reparto estuvo formado por Irene Verdú, Rocío Bernal, Pablo Bermejo. La pieza, dirigida por Sara Serrano, trata de la amistad entre dos mujeres totalmente distintas: por un lado tenemos a la musulmana Amal y por otro, a la cristiana Elvira. Otro personaje importante es el de Matías, marido de Elvira, que está obsesionado por la seguridad, y por eso no acepta la relación entre las dos protagonistas. El drama Mi vida gira alrededor de 500 metros se puso en escena el 16 de noviembre de 2006 en el teatro Fernán Gómez (Centro Cultural de la Villa). La obra permaneció en cartel hasta el 26 de noviembre de 2006 del mismo año. El espectáculo logró un total de 10 funciones. El reparto de la representación, producida por Behemot S.L. Arena, estuvo formado por Marcela Yurfa, María Castillo, Eugenio Gómez, Sol Montoya, Dani Martos. El director fue Guillermo Heras. El drama trata de la violencia en familia a través de la mirada de una niña: "Los ojos de la niña hacen que no nos acerquemos de un modo tan real [...]. La única forma que sabe de amor es la violencia. Si en el futuro el novio le pega ¿Qué hará? Maquilla a la muñeca por si le pega. Vive su vida a través de la violencia" (Díaz Sande, 2006). El título se refiere a la distancia (500 metros) que un juez impone al reconocido maltratador. Este texto ganó el Premio María Teresa León en 2004. 


\subsubsection{Keta Anglada}

La dramaturga menorquina Keta Anglada (1962-) escribió el musical Casa de locos, que se estrenó el 13 de julio de 2006, en el teatro Principal de Mahón. La obra se puso en escena el 3 de agosto de 2006 en el teatro Reina Victoria y se escenificó 18 veces. La historia se desarrolla en los años 80 en un pequeño pueblo. Allí Ana se enamora de Damián, y no sabe que este joven sufrió malos tratos durante su infancia. Por eso, él maltratará también a su compañera. La autora compuso los 23 temas musicales del espectáculo y José Gibeu se ocupó de la dirección musical. El reparto estuvo formado por más de treinta artistas; entre ellos destacan Aida Oliva, Ana Pons, Héctor Arráez, Ives López, Juan Carlos Garciatorre, Marc Pons, Nerea López, Óscar Barreto y Roberto González. El director escénico fue José Serra.

\subsubsection{Cary Antón}

La ilicitana Cary Antón (1957-) es la autora de la obra Tú sí que vales, Loli. La comedia se estrenó el 22 de abril de 2009, en el teatro Muñoz Seca. La pieza permaneció en cartel hasta el 14 de junio del mismo año. El espectáculo logró un total de 56 funciones y el reparto estuvo formado por Cary Antón, Máximo Valverde, Eva Santamaría, Tony River, Yolanda Galviño y Ricardo Rodríguez. La comedia, dirigida por Sara Montiel, nos cuenta la historia de Loli y Boquerón, una pareja que tiene una pensión donde viven unos artistas. Un día llega un cazatalentos que engaña a los clientes para que participen en un concurso y así consigan un contrato en la televisión. Por eso, podemos decir que esta comedia critica a la sociedad actual, donde a través de los concursos de talentos, la gente se aprovecha de la ilusión de todas aquellas personas que quieren tener su minuto de gloria en la pequeña pantalla. 


\subsubsection{Marisol Aznar}

Directora, actriz y guionista, la zaragozana Marisol Aznar (1972-) se interesó pronto por el teatro y por la televisión (participó en los programas Que viene el lobo, Vaya Comunidad, Alsa Kadula, Más te vale XXL, Oregón $T V)$. La dramaturga escribió la comedia En pie de guerra con Francisco Fragua $^{5}$ y con Alfonso Palomares ${ }^{6}$. La obra se escenificó el 21 de mayo de 2009 , en el teatro Alfil y se puso en escena 23 veces hasta el 21 de junio de 2009 con el reparto formado por Marisol Aznar, Laura Gómez Lacueva, Pablo Lagartos, Alfonso Palomares. La pieza, dirigida por Amparo Nogués, hace un recorrido por las guerras libradas por el ser humano desde los comienzos de la humanidad a través de la parodia. El texto fue seleccionado para el XII Certamen de Directoras de Escena de Torrejón de Ardoz (Madrid).

\subsubsection{Elena Belmonte}

La escritora castellano-manchega, de Alcázar de San Juan (Ciudad Real), Elena Belmonte (1958-) es autora de libros de relatos como Que hablen las farolas (Ediciones Libertarias, 1998), Comamos algo (Gens Ediciones, 2006) y de la novela La época del agua (Caballo de Troya, 2005). Escribió monólogos teatrales y obras de teatro como la comedia Los vanidosos, que se estrenó el 11 de mayo de 2006, en el teatro Victoria, y que logró un total de 4 actuaciones hasta el 14 de mayo del mismo año. Dirigida por Manuel Gallana, la obra se desarrolla en la sala de espera de un psicólogo. Allí los personajes Narciso y Anastasia entablan amistad, ya que tienen algunos problemas en común.

\footnotetext{
${ }^{5}$ Francisco Fraguas (1973-) es un actor y guionista zaragozano. Estudió en la escuela municipal de teatro de Zaragoza y fundó con otros compañeros la Compañía Los McClown, donde ha realizado labores de actor y guionista.

${ }^{6}$ Alfonso Palomares (1972-) es un actor, director, guionista madrileño. Ha actuado en 29 espectáculos de teatro en diferentes compañías como Los McClown o LagartoLagarto.
} 


\subsubsection{Marina Bollaín}

La madrileña Marina Bollaín (1967-), licenciada en Canto y Dirección Escénica de Ópera por la Hochschule für Musik “Hanns Eisler” de Berlín y en filología alemana por la Universidad Complutense de Madrid, trabajó como actriz en distintas producciones cinematográficas y para televisión en Madrid y Sevilla. Creó y dirigió el espectáculo de zarzuela ¡Adiós Julián! que se estrenó en la Kulturbrauerei de Berlín. En España, la obra fue representada el 13 de septiembre de 2007, en el teatro Albéniz, en 4 funciones. El reparto estuvo formado por Carmen Campos, Javier Checa, Isabel Egea, Felipe García-Vao. El texto nos cuenta la historia de amor entre tres personajes que pertenecen a otras obras de zarzuela: Julián (personaje de La verbena de la Paloma), Mari Pepa (personaje de La Revoltosa) y Menegilda (personaje de La Gran vía). Afirma Bollaín:

En Berlín me di cuenta de que tenemos un tesoro musical y teatral único, con el que podía ganarme la vida mejor que con el repertorio alemán: allí apenas conocen el género. Reuní números de amor y de celos de una decena de obras y los hilé de manera sencilla, con ayuda de Armin Pommeranz, que hizo los arreglos con sentido del humor y redujo la partitura para una orquesta de diez profesores (Vallejo, 2007).

\subsubsection{Lluïsa Cunillé}

La catalana Lluïsa Cunillé (1961-) ${ }^{7}$, discípula del dramaturgo José Sanchis Sinisterra, fundó en 1993 la compañía L`Hongaresa y fue galardonada en 2010 por el Ministerio de Cultura de España con el Premio Nacional de

\footnotetext{
${ }^{7} \mathrm{Cf}$. la tesis de doctorado, realizada en el SELITEN@T, bajo la dirección del profesor José Romera Castillo, de Ana Prieto Nadal (2015), El teatro de Lluïsa Cunillé en el siglo XXI (2000-2014)., que puede leerse en http://www2.uned.es/centro-investigacionSELITEN@T/pdf/Ana_Prieto_Nadal.pdf [20/04/2018].
} 
Literatura Dramática. En el cuatrienio analizado, se han representado tres obras de la autora: el drama Après moi, le déluge, la comedia Barcelona, mapa de sombras y el musical La corte del Faraón. La pieza Après moi, le déluge se escenificó el 29 de mayo de 2008, en el teatro Valle-Inclán y permaneció en cartel hasta el 6 de julio de 2008, logrando un total de 36 representaciones. En la obra, dirigida por Carlota Subirós, actuaron los actores Jordi Dauder y Vicky Peña. El drama trata de la historia entre un hombre y una mujer que se encuentran en una habitación de hotel de Kinshasa, la capital del Congo, y entablan una larga conversación sobre sus vidas y la realidad que los rodea. La comedia Barcelona, mapa de sombras se estrenó el 2 de marzo de 2006, en el teatro Valle-Inclán y se representó 28 veces hasta el 2 de abril de 2006 . El reparto estuvo formado por María José Alfonso, Montserrat Carulla, Nicolás Dueñas, Roberto Enríquez, Marina Szerezesky y Walter Vidarte. La pieza, dirigida por Laila Ripoll, reúne a seis personajes en un piso barcelonés donde una pareja solicita a sus inquilinos que desalojen sus habitaciones. Por eso, podemos afirmar que cada personaje representa generaciones y condiciones sociales muy distintas. Y el musical La corte del Faraón, que se estrenó el 26 de marzo de 2009, en el teatro de la Abadía, y permaneció en cartel hasta el 05 de abril de 2009 en 10 funciones. La dirección fue de Xavier Albertí y el reparto estuvo formado por Xavier Albertí, Lourdes Barba, Jordi Collet, Montse Esteve, Roberto G. Alonso, Oriol Genís, Lina Lambert y Xavier Pujolràs. La obra se desarrolla en el Antiguo Egipto: allí el faraón quiere casar al general Putifar con la hermosa Lota, como premio a sus hazañas bélicas. Cabe añadir que el texto se basa en La corte de Faraón, zarzuela compuesta en 1910, con libreto de Guillermo Perrín y Miguel de Palacios y música de Vicente Lleó.

\subsubsection{Ana Diosdado}

Ana Isabel Álvarez-Diosdado Gisbert (1938-2015) fue una dramaturga, guionista, escritora y actriz española, aunque nacida en Argentina. Hija de los actores Enrique Diosdado e Isabel Gisbert, ya a los 
cinco años actuó por primera vez sobre las tablas en la obra Mariana Pineda de Federico García Lorca. Estudió Filosofía y Letras en la Universidad Complutense de Madrid y en 1969 fue finalista del premio Planeta con su novela Campanas que aturden, texto que no se llega a publicar. Entre sus primeras obras destacan El okapi (1972), Usted también podrá disfrutar de ella (1973), Los comuneros (Si hubiese buen señor) (1974), Y de Cachemira, chales (1976) y Cuplé (1986). En 2013 recibió el Premio Max de Teatro a su carrera. Olvida los tambores ${ }^{8}$ es la primera obra de teatro de Ana Diosdado. En el cuatrienio analizado, la pieza se puso en escena el 20 de septiembre de 2007, en el teatro La Latina, y permaneció en cartel hasta el 27 de enero de 2008, logrando un total de 131 funciones. La dirección fue de Víctor Conde y el reparto estuvo formado por Antonio Albella, Antonio Hortelano, Ana Polvorosa, Carmen Morales, Guillermo Ortega y Leandro Rivera. La comedia trata de las vidas de Alicia y Tony, una pareja joven que durante una cena de trabajo con el productor musical Nacho tendrá que asumir las cargas de la madurez: de hecho, la hermana de Alicia se presenta allí porque ha dejado a su marido Lorenzo, que también acude al apartamento de los dos para convencer a su mujer que vuelva con él. Las preguntas de Nacho irán descubriendo los miedos, las aspiraciones y las verdades de todos los personajes. La obra se ha representado muchas veces:

Olvida los tambores fue un testimonio de una parte de los jóvenes españoles de los años setenta, de sus inquietudes y expectativas, pero la obra mantiene buena parte de su interés a pesar de los años transcurridos porque, en definitiva, trata sobre problemas humanos atemporales, como las frustraciones de la juventud, los conflictos generacionales y el dificil paso a la madurez (Bonaccorsi, 2017: 51).

\footnotetext{
${ }^{8}$ Olvida los tambores se estrenó el 28 de junio de 1970 en el teatro Principal de Zamora, y en Madrid el 4 de septiembre del mismo año, en el teatro Valle-Inclán. Dirigida por Ramón Ballesteros, su reparto original estaba compuesto por María José Alfonso, Juan Diego, Mercedes Sampietro, Jaime Blanch, Emilio Gutiérrez Caba y Pastor Serrador. En 1975 fue adaptada al cine, bajo la dirección de Rafael Gil.
} 


\subsubsection{Yolanda Dorado}

La cordobesa Yolanda Dorado (1969-) se licenció en Dramaturgia en la Real Escuela Superior de Arte Dramático (RESAD) de Madrid. Ha publicado diversas obras como Por un Jersey (1994) y Bienvenido al Klan (1996), todas editadas por la RESAD. Con El secreto de las mujeres (1998) ha ganado el premio de Arte Joven de la Comunidad de Madrid 1998. Su comedia La pecera se estrenó el 20 de julio de 2006, en el Círculo de Bellas Artes de Madrid, logrando un total de 4 funciones hasta el 23 del mismo mes. Dirigida por Ana Sala, la pieza pertenece a la muestra de trabajos de investigación escénica y dramatúrgica de los alumnos de la RESAD. La pecera habla de un grupo de jóvenes emprendedores en búsqueda del éxito profesional. A lo largo de la obra, el espectador puede observar a los personajes desde el cristal de una pecera, come si estos vivieran inmersos en sus vidas llenas de miseria y frustración.

\subsubsection{Verónica Fernández}

Verónica Fernández (1971-) es una guionista soriana que ha escrito y coordinado varias series de televisión (El Comisario, Cuéntame, El Síndrome de Ulises, etcétera) y que ha ganado un Goya por el guion de la película $E l$ Bola (2000). Ha publicado novelas y obras de teatro como Trabajos de amor perdidos (1997), Dos (1992), Sonata del Rencor (2007) y Sombra y realidad (2008) e imparte clases en el Máster de Guion de la Universidad Carlos III. El drama Presas, que la dramaturga escribió con Ignacio del $\mathrm{Moral}^{9}$, se estrenó el 22 de noviembre de 2007, en el teatro Valle-Inclán, y permaneció en cartel con 34 funciones hasta el 30 de diciembre del mismo año. En la obra, dirigida por Ernesto Caballero, actuaron Gerardo Malla, Mariano Llorente, Pietro Olivera, Celia Bermejo, Lola Casamayor, Pedro G. de las

\footnotetext{
${ }^{9}$ Ignacio del Moral (1957-) es un autor teatral y guionista de cine y televisión. Entre sus primeras obras destacan La gran muralla (1982), Soledad y ensueño de Robinson Crusoe (1983), Sabina y las brujas (1985), Una del Oeste (1986), etc.
} 
Heras, Aurora Herrero, María Herrero, Cristina de Inza, Maruchi León, Ana Otero, Ainhoa Santamaría, Victoria Tejeiro, entre otros. La pieza trata de la vida en una cárcel de mujeres en la España de los años cincuenta “[ ...] pero la acción podría suceder con algún retoque en la Argentina de Videla, o en Marruecos a fecha de hoy" (Vallejo, 2005).

\subsubsection{Aitana Galán}

La salmantina Aitana Galán (1970-) se especializó en Dirección Escénica y Dramaturgia en la RESAD y fue coordinadora artística del Centro Dramático Nacional hasta agosto de 2013. Como dramaturga ha estrenado diversas obras como Vive como puedas (1996) y Jugad, jugad malditos (1994). En el cuatrienio analizado, se pusieron en escena dos obras de la autora: De cerca nadie es normal y Segunda vida. De cerca nadie es normal se estrenó el 13 de marzo de 2009, en el teatro Amaya, y permaneció en cartel con 40 funciones hasta el 26 de abril del mismo año. La dramaturga escribe el texto con Luis García-Araús ${ }^{10}$. El espectáculo fue dirigido por Marta Álvarez y el reparto estuvo formado por Silvia Espigado, Paco Maestre, Fede Rey, Virginia Méndez y Adam Jeziersky. La pieza nos cuenta la historia de amor entre Rober, que a los catorce años cometió un crimen horrible, y Clara. La comedia Segunda vida se estrenó el 8 de octubre de 2008 en el teatro Galileo y permaneció en cartel con 23 funciones hasta el 2 de noviembre del mismo año. El reparto estuvo formado por Jesús Asensi, Jorge Martín, Juan Rivera, Isabel Gálvez, Carolina Lapausa y Lidia Navarro. En esta pieza, dirigida por la misma autora, los personajes se mezclan entre mundo real y mundo virtual: a partir de una madre y una hija que se pasan el día jugando a Second Life, hasta una joven que empieza a jugar con el fin de documentarse y escribir una tesis. Para escribir la obra, la autora se acercó a Second Life

\footnotetext{
${ }^{10}$ El autor madrileño Luis García-Araús (1970-) se licenció en dramaturgia por la RESAD en 2002. Dirigió Un marciano sin objeto (2004) de José Ricardo Morales y Con la sangre de Venecia (1998) de Federico Castro.
} 
después de leer en Internet un artículo sobre los mundos virtuales y empezó a jugar durante un año (Anónimo, 2008).

\subsubsection{Yolanda García Serrano}

La madrileña Yolanda García Serrano (1958-) es dramaturga, directora, guionista de cine y televisión. Escribió diversas obras como De qué va eso del amor (2001), Qué asco de amor (2001), Mujer casada busca gente que la lleve al cine (2004). En los años analizados se han representado dos comedias de la dramaturga: Dónde pongo la cabeza y En la cama. La primera pieza se estrenó el 25 de agosto de 2006 en el teatro Palacio Valdés de Avilés, Asturias, y se representó el 6 de septiembre de 2006 en el teatro Maravillas de Madrid. El espectáculo permaneció en cartel hasta el 22 de octubre del mismo año con 53 funciones. La dirección fue de Tamzin Towsend y el reparto estuvo formado por María Pujalte, Jorge Bosch, Charo Zapardiel, Beatriz Santana y Cecilia Solaguren. El texto trata de la relación entre una mujer maltratada y su marido maltratador, contado en clave de tragicomedia. En la cama, en cambio, se estrenó el 17 de septiembre de 2008 en el teatro Lara con 56 funciones hasta el 9 de noviembre de 2008. En la pieza, dirigida por Tamzin Townsend, actuaron María Esteve y Roberto San Martín. La obra, que se basa en la película En la cama (2005) del director chileno Matías Bize, nos cuenta la historia de dos jóvenes que se conocen en un café y acuden a un hostal para disfrutar de una noche de sexo.

\subsubsection{Ana Graciani}

La dramaturga albaceteña Ana Graciani (1972-) cursó estudios de Periodismo en la Universidad Complutense de Madrid y trabajó en radio, prensa y televisión. Desde el año 2007 se dedica a la escritura, tanto dramática como audiovisual. Sus textos más conocidos son ¡Quiero ser mayor! (2014), Alí Babá (2016), Patente de corso (2017), La ventana abierta (2017). La 
comedia El día del padre, que la autora escribió con Gabriel Olivares ${ }^{11}$, se estrenó el 11 de enero de 2007 en el teatro Circo de Albacete. La obra se representó el 16 de mayo de 2007, en el teatro Maravillas de Madrid, y permaneció en cartel hasta el 8 de julio del mismo año con 56 funciones. El espectáculo fue dirigido por el mismo Olivares, junto a Gracia Olayo, y el reparto estuvo formado por Aitor Mazo, Vicente Romero, Javier Martín y Víctor Ullate Roche. Los tres protagonistas del texto se encuentran en una clínica de reproducción asistida donde tienen que someterse a una prueba de paternidad porque han mantenido relaciones con la misma mujer. Por esta razón, los tres empiezan a competir para obtener la paternidad del hijo.

\subsubsection{Mercedes Lezcano}

La aragonesa Mercedes Lezcano (1952-) estudió Arte Dramático en el Instituto del Teatro de Barcelona. Trabajó como actriz y directora en el teatro, en el cine y en la televisión. El drama Conversación con Primo Levi se estrenó el 8 de mayo de 2005 en el teatro Juan Bravo de Segovia, y se representó el 12 de enero de 2006, en el Círculo de Bellas Artes de Madrid, logrando un total de 19 actuaciones hasta el día 29 del mismo mes. El reparto, bajo la dirección de la misma Lezcano, estuvo formado por Manuel Galiana y Víctor Valverde. La pieza, basada en la novela Se questo è un uomo de Primo Levi, detalla las largas conversaciones entre el intelectual judío y su amigo, el escritor italiano Ferdinando Camon. La representación fue criticada por el embajador israelí, Víctor Harel, que tachó el texto de antisemitismo, pero la autora desmintió todas las acusaciones en diversas entrevistas (Cruz, 2006).

\footnotetext{
${ }^{11}$ Gabriel Olivares (1975-), licenciado en Comunicación Audiovisual y Dirección Cinematográfica, es un dramaturgo albaceteño. Ha fundado y dirigido el TeatroLab de Madrid y desde 2013 realiza espectáculos y proyectos artísticos.
} 


\subsubsection{Angélica Liddell}

Angélica Liddell (1966-) ${ }^{12}$, seudónimo de Angélica González, es una escritora y actriz catalana. Se licenció en Psicología y Arte Dramático en 1993 y a lo largo de su carrera recibió numerosos premios como el Nacional de Literatura Dramática 2012, el León de Plata de la Bienal de teatro de Venecia 2013 y el Premio Leteo 2016. Entre sus primeras obras destacan Lesiones incompatibles con la vida (2003), Tríptico de la aflicción (2004), Mi relación con la comida (2005), Cuarteto para el fin del tiempo (2006). En el cuatrienio analizado se pusieron en escena dos dramas, dirigidos por la misma autora: El año de Ricardo y Perro muerto en tintorería: los fuertes. El primero, se estrenó el 15 de diciembre de 2006 en el teatro de los Manantiales de Valencia y se escenificó el 18 de diciembre de 2007, en el teatro ValleInclán de Madrid, permaneciendo en cartel hasta el día 30 del mismo mes por 12 funciones. El reparto estuvo formado por Angélica Liddell y Gumersindo Puche. La pieza se basa en el Ricardo III de William Shakespeare. Perro muerto en tintorería: los fuertes se estrenó el 8 de noviembre de 2007, en el teatro Valle-Inclán, y logró un total de 34 representaciones hasta el 16 de diciembre del mismo año. En el espectáculo actuaron Nasima Akaloo, Miguel Ángel Altet, Carlos Bolívar, Violeta Gil, Angélica Liddell y Gumersindo Puche. Según la dramaturga, este texto pertenece al género apocalíptico de la política-ficción, donde un imaginario futuro presenta una distopía en la que el enemigo ha sido aniquilado, pero, naturalmente, no se ha conseguido extirpar el miedo, un miedo oscuro y vergonzante, pero no por ello menos agudo (Pérez, 2007).

\footnotetext{
${ }^{12} \mathrm{Cf}$. la tesis de doctorado, realizada en la Universidad Nacional de Educación a Distancia, bajo la dirección del profesor Francisco Gutiérrez Carbajo, de Ana Vidal Egea (2010), El teatro de Angélica Liddell (1988-2000), que puede leerse en http://www2.uned. es/centro-investigacion-SELITEN@T/pdf/TESIS_ANA_VIDAL_SOBRE_LIDDELL.pdf [20/04/2018].
} 


\subsubsection{Carmen Losa}

La sevillana Carmen Losa (1959-) es actriz, dramaturga y directora de teatro. Se licenció en Filología Inglesa por la Universidad de Sevilla y trabajó como actriz en la compañía del Centro Dramático de Extremadura. Actualmente dirige el laboratorio del teatro William Layton de Madrid, en el que imparte clases de interpretación. La comedia Chicas se estrenó en el teatro Galileo, el 23 de marzo de 2006, donde permaneció en cartel con 9 funciones hasta el 8 de abril del mismo año. El 26 de abril de 2006 volvió a ponerse en escena, en el teatro Muñoz Seca, con 51 representaciones hasta el 28 de mayo de 2006. El espectáculo fue dirigido por la misma autora y el reparto estuvo formado por Rosa Estévez, Saida Santana, Cristina Camisón y Resu Morales. La obra se basa en el libro de relatos Primeras caricias (2002) de Beatriz Gimeno y trata de cómo viven la sexualidad las mujeres de distintas épocas y procedencias ${ }^{13}$.

\subsubsection{Paloma Mejía Martí}

Paloma Mejía Martí (1972-) es una artista teatral y coreógrafa madrileña que dirige la homónima compañía de teatro y danza. La dramaturga ha escenificado diversas obras, entre las que destacan Cyrano de Bergerac (2012), Los miserables (2012) y El Conde de Montecristo (2015). Su comedia Recuérdame desnudo se puso en escena el 12 de febrero de 2006, en el teatro Victoria, por 2 veces. La pieza, dirigida por la misma autora, fue representada por la compañía cubana de teatro "Máscara Laroye". Se trata de un espectáculo de teatro y danza que narra la historia de un escritor español que se casa con una mujer cubana. Cuando ella vuelve a su país para resolver unos asuntos, él empieza a escribir tres relatos diferentes (amor,

\footnotetext{
${ }^{13} \mathrm{Cf}$. al respecto, el estudio "Sobre puestas en escena de teatro lésbico (2000-2017)", realizado por Alicia Casado Vegas y Olivia Nieto Yusta (2017), dentro del XXVI Seminario Internacional del SELITEN@T Teatroy marginalismo(s) por sexo, raza e ideología en los inicios del siglo XXI, dirigido por el profesor José Romera Castillo.
} 
odio y pasión). Preocupado por la larga ausencia de su mujer, el protagonista viaja a Cuba para buscarla.

\subsubsection{Teresa Moure Pereiro}

La escritora gallega María Teresa Moure Pereiro (1969-) es doctora en Lingüística y trabaja como profesora de literatura en las facultades de Filosofía y Filología de la Universidad de Santiago de Compostela. Ganó diversos premios como el Premio Lueiro Rey 2004 por la novela corta Axeira das árbores (Sotelo Blanco, 2004), el Premio Ramón Piñeiro de Ensayo 2004 por Outro idioma é posible (Galaxia, 2005), el Premio Xerais de novela, el Premio Aelg y el Premio de la Crítica de narrativa gallega por Herba Moura (Xerais, 2005). La pieza Unha primavera para Aldara se puso en escena el 5 de marzo de 2009, en el Círculo de Bellas Artes, en 2 funciones durante la XIV Muestra de Teatro de las Autonomías. En la representación teatral, dirigida por Xúlio Lago, actuaron Amparo Malo, Lucía Regueiro, María Bouzas, María Barcala, Pilar Pereira, Marcos Correa, Belén Constenla, Josi Lage, Agustín Vega y Xoán Carlos Mejuto. La historia del texto se desarrolla en Galicia, en el siglo XV, en un convento de monjas. Éstas, a pesar de las reglas que prohibían acoger a hombres en un monasterio, deciden dar refugio un guerrero herido durante la Revuelta Irmandiña. Gracias a esta obra, Teresa Moure Pereiro ganó el Premio Rafael Dieste de Teatro en 2007.

\subsubsection{Itziar Pascual}

La madrileña Itziar Pascual (1967-) es dramaturga, pedagoga e investigadora. Estudió periodismo en la Universidad Complutense de Madrid y también Dramaturgia en la RESAD, donde trabaja como profesora de Literatura Dramática. Ha sido presidenta y socia fundadora (2000-2003) de la Asociación de Mujeres en las Artes Escénicas de Madrid (AMAEM). Entre sus primeras obras destacan ¿Me concede este baile? (1991), Confort (1992), Me llamo Blanca (1992), La Fuga (1995). En el cuatrienio analizado 
se han representado dos dramas: Papel de mujer y Pared. La primera, se puso en escena en 12 ocasiones, a partir del 1 de enero de 2006, en el teatro Galileo, bajo la dirección de Pepa Sarsa. El reparto estuvo formado por Nieves Mateo, Cristina Regueira, Ena Fernández y Rosa Álvarez. El drama se divide en dos partes; en la primera - Nana - dos amigas se encuentran en un hospital por razones distintas: una para evitar un posible embarazo y la otra, ya embarazada, se somete a una amniocentesis. En la segunda parte -Despedida - dos hermanas se ocupan de su madre que está en estado crítico en hospital e intentan repartirse las obligaciones de las que tienen que hacerse cargo. El drama Pared se escenificó el 19 de enero de 2006, en el teatro María Guerrero, con 4 funciones hasta el día 21 del mismo mes. En la pieza, dirigida por Roberto Cerdá, actuaron Miriam Montilla y Ana Wagener. Se trata de un drama de mujeres víctimas de violencia doméstica: "Los soliloquios a los que se libran las dos mujeres excluyen toda forma de violencia. La inmovilidad es una constante en una obra donde la única dinámica es la alternancia de textos en una lenta pero segura construcción de un muro expresivo" (Garnier, 2004).

\subsubsection{Paloma Pedrero}

Paloma Pedrero (1957-) $)^{14}$ es una actriz, guionista y directora teatral madrileña. Se licenció en Antropología Social por la Universidad Complutense de Madrid. Es profesora de teatro y entre sus primeras producciones dramáticas destacan La llamada de Lauren (1985), Resguardo personal (1986), Invierno de luna alegre (1987), Besos de lobos (1991), etc. En los años analizados se pusieron en escena tres obras de la dramaturga: Beso a beso, Caídos del cielo y El calor de agosto.

La comedia Beso a beso se estrenó el 16 de noviembre de 2006 en el teatro

\footnotetext{
${ }^{14} \mathrm{Cf}$. la tesis de doctorado, realizada en la Universidad Nacional de Educación a Distancia, bajo la dirección del profesor Francisco Gutiérrez Carbajo, de Sonia Sánchez Martínez (2005), Aspectos semiológicos en la dramaturgia de Paloma Pedrero, que puede leerse completa en http://www2.uned.es/centro-investigacion-SELITEN@T/pdf/SoniaSanchez. pdf [20/04/2018].
} 
Galileo y permaneció en cartel con 12 funciones hasta el 9 de diciembre de 2006. El espectáculo, dirigido por Elena Cánovas, es un conjunto de piezas que cuentan, con humor y erotismo, el primer beso de cinco mujeres de generaciones distintas. El reparto estuvo formado por Jesús Blanco, Rocío Calvo, Ana Chávarri, Gemma Pascual, Carlos Pulido y Chema Rodríguez. La comedia Caídos del cielo, dirigida por la misma autora, se estrenó el 30 de octubre de 2008, en el teatro Fernán Gómez (Centro Cultural de la Villa), dentro del XXV Festival de Otoño de Madrid, con 4 actuaciones hasta el 2 de noviembre del mismo año. Se representó otra vez en el mismo teatro a partir del 19 de mayo hasta el 31 de mayo de 2009, con 11 funciones. En la obra actuaron Rocío Calvo, Ana Chávarri, Paloma Domínguez, Manuel Fernández, Manuel Mata, Carlos Piñeiro, Felipe Pérez, Cristobal Anaga, Salvador Borrego, Yolanda Sola, entre otros. El texto, finalista al Premio Valle-Inclán, como acontecimiento teatral más importante del año 2009, es fruto de la experiencia de Paloma Pedrero a lo largo de ocho años de trabajo en un taller de teatro con un amplio grupo de personas sin hogar. De hecho, la pieza aborda el mundo de los "sin hogar" españoles. El color de agosto", escrita en 1987, es uno de los primeros textos teatrales de Paloma Pedrero. En los años 2006-2009 se puso en escena el 8 de febrero de 2006 en el teatro Arlequín, bajo la dirección de Marta Álvarez. El espectáculo permaneció en cartel hasta el 23 de marzo de 2006, logrando un total de 36 funciones. El reparto estuvo formado por Celia Freijeiro y Marta Larralde. El drama trata de la amistad destructiva entre dos amigas, María y Laura, que se encuentran después de ocho años de separación, ocultando sus verdaderas vidas.

\footnotetext{
${ }^{15}$ Señalamos los siguientes estrenos de El color de agosto: Centro Cultural Galileo, Madrid, 1988, dirección Pepe Ortega; Pace Theatre, New York (EEUU), 1991, dirección Timur Djordjadze; Thèatre du Rènard, Francia, 1994, dirección de Panchika Velez; teatro Giratablas, San José (Costa Rica), 1997, dirección Fernando Vinocour; La Habana (Cuba), 1996, dirección Giraldo Moisés.
} 


\subsubsection{María Reimóndez Meilán}

La gallega María Reimóndez Meilán (1975-) es una escritora que ha publicado obras de narrativa, poesía y teatro. Es fundadora de la Asociación Galega de Profesionais da Tradución e da Interpretación, siendo ella misma traductora e intérprete de profesión. La comedia El club de la calceta se estrenó el 20 de marzo de 2009, en el Círculo de Bellas Artes, durante la XIV Muestra de Teatro de las Autonomías, con 2 funciones. La dirección fue de Celso Parada y el reparto estuvo formado por Estibaliz Espinosa, Susana Dans, Laura Ponte, Maxo Barjas, Elina Luaces, Luisa Merelas e Imma Antonio. Las protagonistas de la obra son seis mujeres muy diferentes: una limpiadora de casas, una secretaria, una mujer mayor, una prostituta, un ama de casa coja y una activista revolucionaria. Ellas asisten a clases de calceta y comparten sus frustraciones, intentando superar sus problemas.

\subsubsection{Carmen Resino}

Carmen Resino (1941-) es una dramaturga madrileña que se licenció en Historia por la Universidad Complutense de Madrid. Escribe obras de teatro desde finales de los sesenta y entre sus primeros textos destacan $E l$ Presidente (1968), La sed (1980), ;Mamá, el niño no llora! (1982), Ultimar detalles (1984), Ulises no vuelve (1983), etc. Fue miembro fundador y presidenta de la Asociación de Dramaturgas Españolas. Ha sido traducida al francés y al inglés. Orquesta se estrenó en el Círculo de Bellas Artes desde el 18 de septiembre hasta el 28 de septiembre de 2008, en 11 funciones. La dirección fue de Luis Maluenda y en el espectáculo actuaron Pepa Sarsa, Enrique Menéndez, Emilio Linder, Dolores Granados e Igor Mikhailov. El protagonista del drama es Maurice, un músico en paro, que vive en un teatro abandonado. A lo largo de la historia se escenifica su pasado a través de fragmentos musicales de los compositores más importantes como Bach, Albinoni, Schmitt y Haendel. 


\subsubsection{Laila Ripoll}

La madrileña Laila Ripoll (1964-) es una directora de escena y dramaturga española. Licenciada por la RESAD, ha dirigido espectáculos para el Centro Dramático Nacional. Su obra fue traducida al francés, rumano, portugués, italiano, griego, inglés y euskera. Entre los textos más destacados de la autora recordamos La ciudad sitiada (1996), Atra Bilis (2001), Santa Perpetua (2011) y El triángulo azul (2014) con la que ganó el Premio Nacional de Literatura Dramática en 2015. En el cuatrienio analizado se pusieron en escena dos obras: el musical El cuento de la lechera (vamos a romper cántaros) y la tragicomedia Los niños perdidos. El cuento de la lechera (vamos a romper cántaros) es una pieza que la autora escribió con Gonzala Martín Scherman ${ }^{16}$, que se estrenó el 4 de marzo de 2006 en el teatro Gran Vía y se escenificó en 6 funciones hasta el día 19 del mismo mes. El espectáculo, dirigido por Gonzala Martín Scherman, es una adaptación de la popular fábula de La Fontaine. La tragicomedia Los niños perdidos se estrenó el 15 de diciembre de 2005, en el teatro María Guerrero. En los años analizados, se puso en escena en el mismo teatro desde el día 1 hasta el 22 de enero de 2006, logrando un total de 19 funciones. La dirección fue de Laila Ripoll y el reparto estuvo formado por Juan Ripoll, Mariano Llorente, Marcos León y Manuel Agredano. El texto trata del periodo de la dictadura $\mathrm{y}$, en particular, de la historia de cuatro niños que viven encerrados en un orfanato.

\subsubsection{Antonia San Juan}

La canaria Antonia San Juan (1961-) es actriz, directora de cine, guionista y monologuista. A los 21 años, se trasladó a Madrid para trabajar no solo en obras clásicas de teatro, sino también en locales donde

\footnotetext{
${ }^{16}$ La malagueña Gonzala Martín Scherman (1969-) es licenciada en Interpretación por la RESAD y en Filología Inglesa por la Universidad Complutense. Entre sus obras más importantes destaca Moma (2008).
} 
interpretaba sus monólogos. En 1999 obtuvo una nominación a los Premios Goya como revelación por el papel de Agrado en la película Todo sobre mi madre de Pedro Almodóvar. En los años analizados se pusieron en escena cuatro comedias, todas escritas y dirigidas por la misma autora: Hijos de su madre, La Terremoto de Alcorcón a precios populares, Las que faltaban y Otras mujeres. Hijos de su madre se estrenó el 2 de octubre de 2007, en el teatro Arlequín, y permaneció en cartel hasta el 3 de febrero de 2008 con 63 funciones; la obra, formada por un conjunto de monólogos, se basa en dos cortometrajes de la misma autora: V.O. (2001) y La China (2005), con actuación de Luis Miguel Seguí, Helena Castañeda y Félix Navarro, que interpretan a diez personajes diferentes, con canciones en directo. $L a$ Terremoto de Alcorcón a precios populares se estrenó en el teatro Arlequín, desde el 3 de abril hasta el 30 de junio de 2008, logrando un total de 36 puestas en escena. Se trata de un espectáculo escrito por Antonia San Juan, siendo la protagonista de la obra La Terremoto de Alcorcón, personaje interpretado por Pepa Charro, que pone en escena con su gran faceta humorística unos monólogos agudos e irreverentes. Las que faltaban se representó en el teatro Alfil, a partir del 3 de enero hasta el 15 de enero de 2006, con 12 actuaciones. La pieza volvió a ponerse en escena en un primer momento siempre en el teatro Alfil el 25 de julio de 2006 y permaneció en cartel por 36 funciones hasta el día 3 de septiembre del mismo año y, en un segundo momento, en el teatro Arlequín, a partir del 2 de octubre de 2007 hasta el 3 de febrero de 2008, en 106 funciones. En la comedia, Antonia San Juan interpreta un conjunto de personajes que hacen una crítica feroz de la sociedad: una mujer que ama a un asesino, una soprano loca, una señora adinerada, un ama de casa experta en toda clase de tareas y una damita del siglo XVI. Otras mujeres se puso en escena el 2 de abril de 2008, en el teatro Arlequín, hasta el 29 de junio, en 45 funciones. El espectáculo está formado por catorce monólogos: tres de la dramaturga canaria, uno basado en Doña Rosita la soltera de Federico García Lorca y diez escritos por Félix Sabroso, Enrique Gallego y Luis Miguel Seguí: “Con el tono de humor, algo sarcástico, pero con un fondo amargo, trece personajes femeninos, con sus distintos puntos 
de vista, acompañan al espectador en un paseo por la psicología humana, constituyendo una radiografía de las diferentes actitudes que adopta el ser humano" (Viola, 2012a: 400).

\subsubsection{Ana Vallés}

Ana Vallés (1959-) es autora, directora de teatro y actriz gallega. Sus espectáculos se han representado en ciudades como Boston, París, Bologna, Porto, Dresden, Edimburgo, Bucarest, Varsovia y Timisoara. Entre sus primeras obras destacan Andante (1991), Café acústico (1992), Deriva (1993) y La casa en primer plano (1994). El drama Me acordaré de todos vosotros, dirigido por la misma autora, se estrenó el 4 de mayo de 2007, en el teatro de la Abadía, y permaneció en cartel hasta el 3 de junio del mismo año por 27 funciones. El reparto estuvo formado por Mónica García, Julio Cortázar, Carlota Ferrer, David Luque, Lola Manzano, Markos Marín, María Miguel, Rafael Rojas y Fernando Soto. La pieza es una miscelánea teatral donde los actores, gracias a un trabajo de creación libre, se convierten en personajes de sí mismos, creando un collage surrealista y felliniano.

\subsubsection{Ana Zamora}

Ana Zamora (1975-) es una dramaturga madrileña que se licenció en Dirección de Escena y Dramaturgia por la RESAD y realizó puestas en escena de textos muy diversos como Carmen de Bizet (2009), Ligazón de Valle-Inclán (2009) y la Tragicomedia de Don Duardos de Gil Vicente (2006). En el año 2001, fundó la compañía Nao d'amores que se ocupa de la puesta en escena de teatro prebarroco. En el cuatrienio analizado, se estrenaron dos obras adaptadas y dirigidas por ella: Auto de los Reyes Magos y Misterio del Cristo de los Gascones. El primer drama se estrenó por tercera vez el 3 de diciembre de 2008, en el teatro de la Abadía, con 45 funciones, hasta el 11 de enero de 2009. El reparto estuvo formado por Jorge Basanta, Francisco Rojas, Alejandro Sigüenza y Nati Vera. La pieza, que se basa en 
el primer texto teatral de la literatura española, representa una mezcla de versos y músicas en directo de los siglos XII y XIII. Misterio del Cristo de los Gascones se estrenó el 29 de marzo de 2007, en el teatro de la Abadía, y permaneció en cartel con 10 actuaciones hasta el 8 de abril del mismo año. En la representación actuaron Elvira Cadrupani, David Faraco, Alejandro Sigüenza y Nati Vera. Se trata de una recreación libre de la ceremonia litúrgica que se representaba en la Iglesia de San Justo en Segovia, donde se construyó el Cristo de los Gascones. El espectáculo se caracteriza por la interpretación en directo de piezas musicales y une el trabajo coral de los actores con el teatro de títeres.

\subsection{Latinoamérica}

\subsubsection{Gabriela Acher}

La uruguaya Gabriela Acher (1944-) es una actriz, guionista, humorista y escritora que vive en Buenos Aires, donde trabaja en televisión, cine y teatro. Ha publicado diversos libros como El príncipe azul destiñe (1992), La guerra de los sexos (1998) y Algo sobre mi madre (todo sería demasiado) (2007). La comedia El amor en tiempos del colesterol se estrenó el 16 de septiembre de 2009, en el teatro Fernán Gómez (Centro Cultural de la Villa), con 23 representaciones hasta el 11 de octubre del mismo año. La obra, dirigida por la dramaturga, se basa en el homónimo libro que publicó en 2001. El espectáculo se presenta como un programa de televisión donde la misma autora recibe y contesta a cartas de distintas mujeres que le cuentan sus insatisfacciones amorosas y sexuales.

\subsubsection{Marta Betoldi}

Marta Betoldi (1959-) es una actriz argentina de televisión, teatro y cine. Actualmente trabaja como guionista de series de televisión. Entre sus primeras películas como actriz destacan Proceso a la infamia (1974), 
Los médicos (1978), Días de ilusión (1980) y No habrá más penas ni olvido (1983). En los años 2009, 2010, 2013 recibió la nominación como mejor autora en los Premios Martín Fierro. El espectáculo Contracciones se representó el 16 de febrero de 2006, en el teatro Fernán Gómez (Centro Cultural de la Villa) y permaneció en cartel en 16 funciones hasta el 5 de marzo de 2006. En la pieza, dirigida por Mario Pasik, actuaron Marta Betoldi, Laura Azcurra y Facundo Espinosa. Fue traducida al francés, presentada en 2002, en el Congreso de la Mujer, realizado en París y estrenada en 2003 por la Compañía francesa de Muriel Hunet. En el mismo año fue traducida y publicada en Londres y representada en el Royal Theatre de Londres por la compañía inglesa de Tiffany Watt-Smithl. En la obra asistimos a unos monólogos entre dos mujeres que, en distintas épocas y lugares (una en 1976, año del golpe de estado en Argentina, y otra en la actualidad), escriben un diario a sus futuros hijos.

\subsubsection{Manuela Infante}

La dramaturga chilena Manuela Infante (1980-) se licenció en Artes por la Universidad de Chile. Desde el año 2001, junto con su compañía Teatro de Chile, trabajó como dramaturga y directora montado las obras Prat (2002), Juana (2004), Narciso (2005), Rey planta (2006) y Cristo (2008). Sus trabajos se han presentado en Alemania, Holanda, Irlanda, España, Italia, Estados Unidos, Perú, México, Argentina y Brasil. La obra Narciso se estrenó el 5 de noviembre de 2006, en el Nuevo Teatro Alcalá, con una sola función. En la pieza, dirigida por la misma autora, actuaron Rodrigo Sobarzo y Angélica Vial. Se trata de la historia de un adolescente que, por la atormentada relación con su familia y su escuela, decide encerrarse en el baño de su casa y pasar allí sus días. Según el crítico Eduardo Guerrero del Río:

En todo caso, más allá del latente narcisismo, lo que se concreta en el pequeño espacio escénico (diferente a los espacios 
convencionales) es un juego de liberación, quedando en claro la rebelión de los jóvenes frente al sistema y, sobre todo, frente a sus padres. Es un grito ahogado, fiel reflejo de un mundo carente para ellos de sentido y de referentes políticos y sociales (Guerrero del Río, 2005: 51).

\subsubsection{Marina Seresesky}

Marina Seresesky (1969-) es directora de cine, guionista y actriz argentina. En el teatro, estuvo vinculada profesionalmente a la compañía Teatro Meridional y bajo la dirección de Gerardo Vera, en el Centro Dramático Nacional, participó en la obra Agosto (2011). La puerta abierta (2016), su primer largometraje, protagonizado por Carmen Machi y Terele Pávez, obtuvo la nominación en los Premios Goya 2012. La obra Negra! se puso en escena el 16 de octubre de 2007, en el teatro Fernán Gómez (Centro Cultural de la Villa), en 18 funciones, hasta el 4 de noviembre del mismo año. La dramaturga, que es también protagonista y directora de la pieza, interpreta tres monólogos con tres personajes femeninos diferentes: una mulata latinoamericana, una caribeña de color y una africana que se enfrentan a problemas como la esclavitud o la maternidad ${ }^{17}$.

\section{DRAMATURGAS EN LENGUA INGLESA}

\subsection{Inglaterra}

\subsubsection{Agatha Christie}

Agatha Christie (1890-1976) fue una escritora y dramaturga británica especializada en novelas policíacas. A lo largo de su carrera, publicó novelas policiales e historias cortas. Por lo que se refiere al teatro, publicó doce obras

\footnotetext{
${ }^{17} \mathrm{Cf}$. al respecto, "Dramaturgas argentinas estudiadas en el SELITEN@T" (Romera Casti1lo, 2016).
} 
entre las que destacan obras como Diez negritos (1943), Cita con lo muerte (1945), La telaraña (1954) y Regla de tres (1962). En los años analizados, se han puesto en escena dos espectáculos de la autora: La ratonera y Una visita inesperada. La ratonera ${ }^{18}$ se representó a partir del 1 de enero de 2006, en el teatro Muñoz Seca, y permaneció en cartel con 101 funciones hasta el 9 de abril de 2006. El reparto estuvo formado por Jaime Blanch, Pablo Calvo, Ane Gabarain, Klara Badiola, Fermín Sanles, Cristina Rivera y José Luis Mendiaraz. El espectáculo, dirigido por Ramón Barea, trata de la historia de ocho personajes que quedan atrapados en una casa de huéspedes, debido a la nieve, y que se ven envueltos como sospechosos o víctimas en un reciente crimen ocurrido en Londres. "La ratonera es la clásica pieza policiaca en la que no se sabe quién es el asesino hasta el final de la obra, de modo que el espectador puede sospechar de cada uno de los personajes, pues todos tienen motivos y ocasión para cometer el crimen" (Besó Portalés, 2008). Una visita inesperad ${ }^{19}$ se puso en escena en el teatro Real Cinema el 1 de septiembre de 2006 con 75 actuaciones hasta el 12 de noviembre del mismo año, bajo la dirección de Gerardo Malla. El reparto estuvo formado por Jaime Blanch,

\footnotetext{
${ }^{18}$ La Ratonera tuvo su estreno mundial en el Theatre Royal de Nottingham, el 6 de octubre de 1952. Comenzó a representarse en Londres el 25 de noviembre de 1952 en el New Ambassadors Theatre. La obra, con traducción de Luis de Baeza, se estrenó en España el 6 de agosto de 1954 en San Sebastián y tras una gira por el país pasó al teatro Infanta Isabel de Madrid el 12 de noviembre del mismo año. El elenco estuvo formado por Mariano Azaña, María Luisa Ponte, Irene Caba Alba, Irene Gutiérrez Caba, Julia Gutiérrez Caba y Erasmo Pascual. La obra superó las 700 representaciones con más de 2 años en cartel. Se repuso en 1965, en el teatro Arlequín de Madrid, en 1972 en el teatro Cómico de Madrid, en 1998 en el teatro Real Cinema de Madrid, en 2005 al Muñoz Seca de Madrid.

${ }^{19}$ Una visita inesperada se estrenó 12 de agosto de 1958 en el Duchess Theatre, de Londres, bajo la dirección de Hubert Gregg y con el siguiente reparto: Philip Newman, Renée Asherson, Nigel Stock, Winifred Oughton, Christopher Sandford, Violet Farebrother, Paul Curran, Tenniel Evans, Michael Golden, Roy Purcell. En España se estrenó en 1959 en el teatro Infanta Isabel, Madrid. El reparto estuvo formado por Manuel Dicenta, Julia Gutiérrez Caba, Consuelo Company, Luisa Rodrigo, Fernando Nogueras, Ángel de la Fuente, José Cuadrado y Ricardo Lucía. Se volvió a representar en 1972 en el teatro Arlequín, Madrid, con los siguientes intérpretes: Manuel Conde, Ana María Vidal, Ángel Picazo, Blanca Sendino, Fabián Fonsana, Magda Roger, Vicente Vega y Enrique Ciurana.
} 
Charo Solano, Tomás Sáez, César Diéguez, Cristina Inza, Miguel Ángel Fernández, Fermín Sanles y Karmele Aramburu. En la pieza el protagonista se pierde por una carretera de Gales y acude a una mansión cercana a pedir ayuda. Allí encuentra a Richard, un hombre en silla de ruedas, muerto con una bala en la cabeza y, al lado, a su joven esposa Laura, que se declara autora del crimen. Aunque Laura suplica a Michael que llame a la policía, él comienza a investigar por su cuenta en una casa en la que todos son sospechosos porque todos tenían motivos para asesinar al señor de la casa:

En La visita inesperada, Agatha Christie introduce una pequeña variación en la estructura de la trama: apenas empieza la obra, una mujer confiesa haber cometido un crimen, aunque las cosas no son tan sencillas [...]. Hay que estar muy atento en los diálogos, porque se explica la personalidad del fallecido así como datos fundamentales del resto de personajes. Además, cada detalle escondeuna pistabuena ofalsa.Apesardela enormeinverosimilitud de la trama, como suele ocurrir en las obras policiacas, el suspense creado por conocer la identidad del asesino, con las sospechas que se desplazan de uno a otro personaje, permite que el espectador se amolde bien a lo que está viendo (Besó Portalés, 2008).

\subsubsection{Sarah Kane}

La británica Sarah Kane (1971-1999), en 1992, se licenció en Arte Dramático por la Universidad de Bristol y dos años después escribió su primer texto Sick, una trilogía de monólogos, cuyos temas centrales son la violación, la bulimia y la sexualidad. Durante este periodo, la autora ya padece síntomas de depresión y se suicidará en 1999. Por su singular talento y sus provocadoras temáticas, Sarah Kane es una de las dramaturgas más representadas en Europa, siendo sus textos traducidos al alemán, francés, italiano, español, catalán, griego, danés, portugués, rumano y ruso. En el cuatrienio analizado, se representaron dos obras de la dramaturga: 4.48 
Psicosis y dos versiones de El amor de Fedra. El drama 4.48 Psicosis se estrenó el 4 de febrero de 2009 en el teatro Fernán Gómez (Centro Cultural de la Villa) con 15 funciones, hasta el día 22 del mismo mes. En la obra actuó Leonor Manso, bajo la dirección de Luciano Cáceres. El título se refiere a la hora en que se cometen más suicidios ya que, según estadísticas publicadas en Inglaterra, en esa hora aproximada acaba el efecto de los fármacos psiquiátricos tomados la noche anterior. La pieza muestra qué es lo que pasa por la mente de una persona cuando se mezclan la realidad con lo imaginario. Tras terminar el texto, Sarah Kane se suicidó. El drama El amor de Fedra se representó en dos versiones: la primera se estrenó el 3 de julio de 2008 en el teatro Réplika por 20 actuaciones hasta el 3 de agosto del mismo año. La dirección fue de José Manuel Taracido y el reparto estuvo formado por Pablo Castañón, Ani Rubio, Irene Ambel, Daniel Ghersi, Àlex Reig, Alejandro Pantany, Lorena Roncero y Tamara Berbes. La segunda versión, que se puso en escena en serbio con el título Fedrina Ljubav, se estrenó el 27 de noviembre de 2009 en el teatro Fernán Gómez (Centro Cultural de la Villa) en 3 funciones, durante el Festival de Otoño de la Comunidad de Madrid. La dirección fue de Iva Miloševic y actuó la compañía de teatro Jugoslovensko Dramsko Pozoriste. La historia trata de una mujer llamada Fedra que se enamora de su hijastro Hipólito. Éste, en cambio, mantiene una relación ambigua la hija de Fedra. El rechazo que expresará Hipólito frente a la declaración de amor de su madrastra, desencadena una serie de sucesos que componen la tragedia, ya que la protagonista se quiere vengar por los hechos ocurridos.

\subsubsection{Polly Stenham}

La escritora británica Polly Stenham (1986-) se interesó en el teatro muy pronto ya que su padre organizaba eventos culturales en el Royal College of Art y en el Institute of Contemporary Arts en Londres. Estudió en el University College London y a los 19 años escribió su primer texto The Face que resultó premiado por The Royal Court Theatre de Londres, también 
con el Charles Wintour Award, The Critics Circle Award y el TMA Award, como la mejor obra del 2007. El drama Esa cara se estrenó el 30 de marzo de 2009, en el Círculo de Bellas Artes durante la XIV Muestra de Teatro de las Autonomías en 7 funciones. La dirección fue de Pilar Massa y el reparto estuvo formado por Ivana Heredia, Ainhoa Santamaría, Antía González, Pilar Massa, Ignacio Jiménez y Borja Elgea. En la pieza, la dramaturga cuenta la historia de Mia, una chica que, interna en un colegio, maltrata junto a su amiga Izzy a otra compañera. La protagonista será expulsada y su vuelta a casa desencadena el nacimiento de discusiones y problemas camuflados bajo la apariencia de una familia respetable.

\subsection{Estados Unidos}

\subsubsection{Margaret Edson}

La dramaturga estadounidense Margaret Edson (1961-) se licenció en Historia en 1983 y trabajó como profesora de inglés durante seis años. Gracias a su obra Wit resultó ganadora del Premio Pulitzer de Teatro en 1999. Wit se estrenó el 8 de noviembre de 2003 en el teatro Bartrina de Reus de Tarragona y se representó el 12 de enero de 2006, en el teatro Maravillas de Madrid, logrando un total de 55 funciones hasta el 5 de marzo de 2006. La dirección fue de Lluís Pascual y el reparto estuvo formado por Rosa María Sardá, Miguel Palenzuela, Mercé Pons, Dora Santacreu y Javier Albalá. La pieza narra la historia de una profesora de literatura especializada en la obra del poeta inglés del siglo XVI John Donne, invadida por una grave enfermedad terminal. A pesar del cáncer, la protagonista aborda su tragedia con humor: "El valor fundamental de Wit es que habla de las relaciones entre seres humanos, y en éstas entra en juego [...] la necesidad de entender la enfermedad a través de un lenguaje claro y directo y de mantener un cierto grado de control sobre la propia vida" (Fernández Morales, 2006: 273).

\subsubsection{Eve Ensler}


Eve Ensler (1953-) es una dramaturga estadounidense conocida internacionalmente por su obra teatral The Vagina Monologues (1996). Se graduó en 1975 por la Universidad Middlebury College. En 1998 fundó el proyecto V-Day que combate la violencia doméstica y el femicidio. Entre sus primeras obras teatrales destacan: Ladies (1989), Scooncat (1992), Floating Rhoda and the Glue Man (1993), The Depot (1995) y Extraordinary Measures (1995). Ganó diversos premios como el Matrix Award en 2002 y el Media Spotlight Award for Leadership (concedido por Amnesty Internacional, en el mismo año). Los monólogos de la vagina ${ }^{20}$ se estrenó el 8 de noviembre de 2006, en el Nuevo Teatro Alcalá, bajo la dirección de Antonia García y permaneció en cartel logrando un total de 173 representaciones hasta el 27 de mayo de 2007. El texto ha sido adaptado al castellano por Víctor Cremer y fue llevado a la escena por Maite Merino y Magdalena Broto. La obra está formada por un número variable de monólogos que se relacionan con la vagina, ya sea a través del sexo, el amor, la violación, la menstruación, la mutilación, la masturbación, el nacimiento, el orgasmo y la variedad de nombres para la vagina, o simplemente como un aspecto físico del cuerpo. Eve Ensler escribió la primera versión de esta pieza en 1996, después de entrevistar a más de 200 mujeres acerca del sexo, las relaciones amorosas y la violencia doméstica.

\subsubsection{Helene Hanff}

Helene Hanff (1916-1997) fue una escritora estadounidense que durante los años cuarenta y cincuenta trabajó como guionista de obras de teatro, aunque también es autora de varios guiones para la televisión, libros infantiles, ensayos y novelas como Underfoot in Show Business (1961), The

\footnotetext{
${ }^{20}$ Los monólogos de la vagina se estrenó el 3 de octubre de 1996 en el Centro de Arte HERE de Nueva York. En la representación la dramaturga interpretaba a una docena de personajes relatando sus historias. Antes de llegar a Madrid, donde se estrenó el día 7 de septiembre del 2000, en el teatro Alfil, la obra obtuvo gran éxito en Broadway en 1997, y en Londres, donde se representó en marzo de 1999, en el Ring's Head Theatre.
} 
signing of the Constitution (1961), Terrible Thomas (1964) y Early Settlers in America (1965).

La pieza 84 Charing Cross Road se basa en la homónima novela publicada en 1970. Se estrenó en el teatro Fígaro el 26 de enero de 2006 y permaneció en cartel, con 55 funciones, hasta el 19 de marzo del mismo año. En la pieza, dirigida por Isabel Coixet, actuaron Carmen Elías y Josep Minguell. La protagonista es la escritora Helene Hanff, que vive en Nueva York y busca algunos textos que se encuentran en una librería de libros usados especializada de Londres, en el número 84 de Charing Cross. La mujer inicia una relación epistolar con Frank Doel, empleado de la tienda. Los dos no se encontrarán nunca, pero terminarán siendo amigos, compartiendo el amor por los libros y por la literatura.

\subsubsection{Lillian Hellman}

La dramaturga y guionista de cine estadounidense Lillian Florence Hellman (1905-1984) estudió en la Universidad de Columbia y en la Universidad de Nueva York. Su carrera literaria se divide en dos periodos muy distintos: en una primera etapa, a partir de 1934, la autora abordó la producción teatral; durante el segundo periodo, entre 1969 y 1980, escribió libros de memorias y alguna narración. Entre sus obras destacan The Dark Angel (1935), These Three (1936), Days To Come (1936) y The Little Foxes (1939). El primer trabajo teatral de la autora, The Children's Hour (1934), tuvo un gran éxito. El espectáculo, traducido al español con el título $L a$ Calumnia $^{21}$, se representó en dos periodos distintos en los años analizados: en un primer momento se puso en escena el teatro Albéniz, el 10 de enero de 2006, en 6 funciones. La pieza se volvió a representar el 19 de agosto de 2006, en el teatro Muñoz Seca, y permaneció en cartel logrando un total de

\footnotetext{
${ }^{21}$ En España, La calumnia se estrenó en 1961, en el teatro Beatriz de Madrid, en versión de Manuel Aznar y Cayetano Luca de Tena, con decorados de Emilio Burgos e interpretación de Montserrat Salvador, María Isabel Pallarés, Amparo Baró, Manuel Gallardo, Mayrata O’Wisiedo, Josefina Díaz, María José Alfonso, María Massip y María Jesús Lara.
} 
70 actuaciones hasta el 22 de octubre del mismo año. La representación fue dirigida por Fernando Méndez-Leite y el reparto estuvo formado por Cristina Higueras, Fiorella Faltoyano, Teresa Cortés, César Díaz, Carolina Lapausa, Amparo Alcoba y María del Puy. La obra habla del escándalo suscitado en una pequeña localidad de provincia norteamericana por las falsas acusaciones de lesbianismo proferidas por una alumna contra dos profesoras. En 1961 se estrenó la adaptación cinematográfica, dirigida por William Wyler y protagonizada por Audrey Hepburn, Shirley MacLaine y James Garner.

\subsubsection{Marsha Norman}

Marsha Norman (1947-) es una periodista y escritora estadounidense que actualmente trabaja como profesora en la Juilliard School en Nueva York. Escribió Getting Out (1977), Circus Valentine (1979), Traveller in the Dark (1984), The Secret Garden (1991) pero su obra más conocida es Night, Mother ${ }^{22}$ (1982) con la que ganó el Premio Pulitzer en 1983. El espectáculo, traducido al español con el título Buenas noches, madre, en el cuatrienio analizado se escenificó en dos versiones: la primera se estrenó en el teatro Arlequín el 12 de enero de 2007 y permaneció en cartel, con 54 representaciones, hasta el 4 de marzo del mismo año. En la pieza, dirigida por Gerardo Malla, actuaron Carmen de la Maza y Remedios Cervantes. La segunda versión se estrenó en el teatro Bellas Artes, el 9 de enero de 2009, por 3 funciones, bajo la dirección de Celso Cleto, y con un reparto formado por Manuela, María y Sofía Alvés. La obra habla de la relación entre Thelma y su hija Jessie. Ésta le explica a su madre con toda tranquilidad que a la mañana siguiente estará muerta, puesto que planea su propio suicidio aquella

\footnotetext{
${ }^{22}$ La producción original de 'Night, Mother fue protagonizada por Kathy Bates como Jessie y Anne Pitoniak como Mamá en el American Repertory Theater en Cambridge, Massachusetts. La producción llegó finalmente a Broadway, donde fue representada en el John Golden Theatre con el mismo reparto. Recibió 4 nominaciones para los Premios Tony: mejor obra de teatro, mejor actriz en una obra de teatro (tanto para Bates y como para Pitoniak) y mejor director (Tom Moore). En cuanto a versiones en español, en España se estrenó en 1984, protagonizada por Mary Carrillo y Concha Velasco.
} 
misma noche:

Esta detonante confesión, marca una gran intensidad dramática, forma un conflicto entre ambos personajes, se inicia una oposición de fuerzas e intereses, puesto que Mónica siempre defiende su ideal, en cambio la madre hace lo que sea por disuadirla de aquella idea. Aquella tensión entre ambos personajes se da desde el principio hasta el final de la obra y es el eje que da unidad al drama (Cáceres Ruiz, 2011).

Existe también una versión cinematográfica de 1986, protagonizada por Sissy Spacek y Anne Bancroft como hija y madre, respectivamente.

\subsection{Australia}

\subsubsection{Gloria Montero}

La escritora Gloria Montero (1933-), hija de emigrantes asturianos, nació en Australia. Terminó sus estudios en el Lourdes Hill College, en Brisbane. Después de cursar estudios superiores de música y artes dramáticas, empezó a trabajar en la radio como locutora y actriz. En los años setenta se trasladó a Canadá, donde trabajó como cantante, actriz, escritora, locutora de radio. Escribió The Immigrants (1977), We stood together (1979), Billy Higgins Rides the Freights (1983), The Summer the Whales Sang (1985). La comedia Frida K. se estrenó el 17 de octubre de 1995 en el teatro Alfil y se escenificó el 22 de febrero de 2006, en el teatro Galileo, permaneciendo en cartel en 22 funciones hasta el 19 de marzo del mismo año. En la obra actuó Maite Brik, bajo la dirección de Peter Hinton. La protagonista de la pieza es Frida que, devastada por la mala salud, nos habla de su vida, a partir de sus primeras exposiciones hasta su matrimonio atormentado con el muralista Diego Rivera. 


\section{DRAMATURGAS EN LENGUA FRANCESA}

\subsection{Francia}

\subsubsection{Marguerite Duras}

Marguerite Duras (1914-1996), pseudónimo de Marguerite Germaine Marie Donnadieu, fue una novelista, guionista y directora de cine francesa. Estudió Derecho, Matemáticas y Ciencias políticas y durante la Segunda Guerra Mundial, participó en la Resistencia francesa. Su obra literaria cuenta con unas cuarenta novelas y una docena de piezas de teatro, entre las que destacan El Square (1955), L'Éden Cinéma (1977) y Savannah Bay (1982). El drama La música se estrenó el 1 de mayo de 2008, en el teatro Fígaro, y permaneció en cartel en 35 actuaciones hasta el 15 de junio del mismo año. El reparto estuvo formado por Celia Freijeiro y Alberto Merino. La pieza fue escrita originalmente en 1965 para la televisión inglesay trata de una pareja que se ha separado hace dos años y que se reencuentra para terminar los trámites del divorcio. Los dos empiezan a recordar los momentos felices y tristes de esta historia de amor, a partir del enamoramiento hasta la convivencia. En el espectáculo, dirigido por Marta Álvarez, suben al escenario también dos músicos-actores que tocan el violoncelo (Diego Valbuena) y el violín (Julia de Castro).

\subsubsection{Yasmina Reza}

Yasmina Reza (1959-) es una actriz, novelista y dramaturga francesa. Estudió Sociología y Teatro en la Universidad de Nanterre. Después de trabajar como actriz en cine y en el teatro, Yasmina debutó como escritora con Conversaciones Tras Un Entierro (1987) con la que ganó el premio Molière en el mismo año ${ }^{23}$. Además, tradujo La metamorfosis de Franz Kafka para

\footnotetext{
${ }^{23}$ Entre otros galardones obtenidos figuran los premios Laurence Olivier, Evening Standard y el Nestroy-Theatreprize. En 2000 recibió el Gran premio del teatro de la Academia
} 
Roman Polanski. En el cuatrienio analizado se han representado tres obras de la autora: Arte, Tres versiones de la vida y Una comedia española. En la versión española, Arte $^{24}$ fue adaptada por Fernando Mallorens y Federico González del Pino, bajo la dirección de Eduardo Recabarren, con un reparto formado por Luis Merlo, Iñaki Miramón y Alex O’Dogherty. La obra se puso en escena el 13 de febrero de 2009, en el teatro Alcázar, y permaneció en cartel en 112 funciones hasta el 21 de junio de 2009. Los protagonistas son el médico Sergio, el ingeniero aeronáutico Marco e Iván, un empleado de una papelería. A lo largo de la historia, los tres hablan de un cuadro blanco que Sergio ha comprado por cinco millones de pesetas. Si por un lado el médico es partidario del arte contemporáneo, por otro el ingeniero lo detesta porque prefiere las obras clásicas. Iván, en cambio, intenta apaciguar los ánimos de sus amigos, pero su intervención complica la situación. De hecho, ellos terminarán dibujando sobre la tela. Finalmente la vuelven a limpiar y el cuadro quedará expuesto en casa de Sergio. La comedia Tres versiones de la vida se estrenó el 14 de febrero de 2007, en el teatro Infanta Isabel, logrando un total de 49 actuaciones hasta el 8 de abril del mismo año. La pieza fue dirigida por Natalia Menéndez y el reparto estuvo formado por Silvia Marsó, José Luis Gil, Joaquín Climent, Carmen Balagué, David Marco. En el texto se habla de la pareja Sonia y Enrique que invita a cenar la pareja formada por Inés y Humberto, un prestigioso científico que publicará un artículo de Enrique en una revista importante. La autora nos presenta tres versiones de la misma historia: en la primera, los dos se presentan a la cena el día precedente

francesa, en reconocimiento a toda la carrera dramática de la autora.

${ }^{24}$ Arte se estrenó en París, en la Comédie des Champs-Elysées, en octubre de 1994, donde permaneció en cartel 18 meses; en Berlín, en el teatro de la Schaubühne, en octubre de 1995; en Londres, en el Wynd- ham's Theatre, en octubre de 1996; en Nueva York, en el Royal Theatre, en marzo de 1998. La versión española, firmada por José María Flotats, se estrenó en el teatro Marquina el 29 de septiembre de 1998 y, además del mismo Flotats, formaron parte del reparto Carlos Hipólito y José María Pou, sustituido por compromisos televisivos, a finales de enero del 2000, por Jesús Castejón. La producción permaneció en cartel hasta el 4 de junio de 2000 y fue un gran éxito de la escena madrileña con 600 funciones (Viola, 2012a: 409). 
a la invitación — cuando en casa no hay nada preparado-, en la segunda al día siguiente y en la tercera, improvisan la cena. El punto de contacto de las tres versiones serán las humillaciones y las mezquindades profesionales. Una comedia española se estrenó el 13 de febrero de 2009, en el teatro Valle-Inclán, bajo la dirección de Silvia Munt, y permaneció en cartel en 39 funciones hasta el 29 de marzo del mismo año. El reparto estuvo formado por Ramon Madaula, Xicu Masó, Maria Molins, Cristina Plazas y Mònica Randall. Se trata de una obra de metateatro, donde cinco actores ensayan un texto de un autor español que gira en torno a los problemas cotidianos que se viven en cualquier casa. Con frecuencia, entre ensayo y ensayo, los actores que protagonizan la obra reflexionan sobre sus personajes, mezclando realidad y ficción.

\subsection{Egipto}

\subsubsection{Denise Chalem}

Denise Chalem (1952-) es una escritora egipcia que escribe en lengua francesa. Nacida en El Cairo, pronto dejó su país y se instaló en Francia donde ha trabajado como actriz en espectáculos de Gabriel Garran, Jean-Pierre Vincent, Bernard Murat y Marcel Bluwal. Su primera obra À cinquante ans, elle découvrait la mer (1980) se tradujo a ocho idiomas. Escribió La Nuit de cristal (1981), Prague, mille quatre-vingt quatorze kilomètres (1983), Selon toute ressemblance (1986) y Couki et Louki sont sur un bateau (1987). Dile a mi hija que me fui de viaje, traducida por Lourdes Ortiz, es la versión española de Dis à ma fille que je pars en voyage (2006), que se estrenó el 30 de octubre de 2007, en el teatro Galileo, logrando un total de 36 funciones hasta el 09 de diciembre de 2007. La representación fue dirigida por Jesús Salgado y el reparto estuvo formado por María José Goyanes, Marta Belaustegui y Marina Andina. La pieza se desarrolla entre las cuatro paredes de una celda: allí se encuentran dos mujeres distintas, recluidas a causa de sus problemas con los hombres: por un lado tenemos a Dominique, de clase baja, y por otro 
Caroline, una mujer burguesa.

\section{DRAMATURGAS EN LENGUA ITALIANA}

\subsection{Italia}

\subsubsection{Silvana Grasso y Licia Maglietta}

Silvana Grasso (1952-) es una escritora siciliana que trabajó también como Concejal de Patrimonio Histórico y Bienes Culturales en la ciudad de Catania. Ha publicado novelas, cuentos, obras de teatro. Destacan las obras: Nebbie di ddraunàra (1993), L'albero di Giuda (1997), 7 uomini 7. Peripezie di una vedova (2006) y Il cuore a destra (2014). La napolitana Licia Maglietta (1954-) es una actriz de éxito en Italia. Ha trabajado en el cine, en el teatro y en la televisión. Ha actuado en La locandiera (1993), Leonce e Lena (1994), Caligola (1997) y ha escrito e interpretado la obra Delirio amoroso (1995), sobre la vida de la poetisa italiana Alda Merini. Las dos han creado la adaptación teatral de la novela Pazza è la luna (2007) de Silvana Grasso. La obra, con el título Manca solo la domenica (Falta solo el domingo), se estrenó el 25 de septiembre de 2009, en el teatro ValleInclán en 3 funciones. La representación, dirigida e interpretada por Licia Maglietta, cuenta la historia de una mujer siciliana, Borina Serrafalco, que se ha quedado sola en un pueblo de Catania, insignificante y sin identidad. Por eso, ella quiere construirse otras vidas y decide que será la viuda de seis hombres, con seis vidas diferentes, uno para cada día de la semana, y cada uno de ellos enterrado en un cementerio distinto. El título de la pieza se refiere al hecho de que a Borina solo le falta el hombre del domingo. 


\section{CONCLUSIÓN}

Las dramaturgas, cuyas piezas fueron llevadas a escena en los teatros madrileños durante los años 2006-2009, proceden de distintos países de Europa (veintisiete españolas, tres inglesas, dos francesas y una italiana) y América (cuatro hispanoamericanas y cinco estadounidenses). Cabe añadir que dos autoras proceden de Egipto y de Australia. A continuación, constatamos las cinco autoras, incluidas en la cartelera citada, con el número de funciones más alto. Al lado de cada una de ellas, hemos señalado el número de funciones y el país de procedencia:

\begin{tabular}{|l|l|l|}
\hline Autora & $\begin{array}{l}\text { Números de } \\
\text { funciones }\end{array}$ & País \\
\hline Yasmina Reza & 200 & Francia (Europa) \\
\hline Agatha Christie & 176 & $\begin{array}{l}\text { Inglaterra } \\
\text { (Europa) }\end{array}$ \\
\hline Eve Ensler & 173 & $\begin{array}{l}\text { Nueva York } \\
\text { (Estados Unidos) }\end{array}$ \\
\hline Antonia San Juan & 156 & España (Europa) \\
\hline Ana Diosdado & 131 & España (Europa) \\
\hline
\end{tabular}

Tabla 1

La dramaturga más representada en el cuatrienio analizado resulta ser la francesa Yasmina Reza. Las 200 funciones de la autora comprenden tres obras: Arte (112 funciones), Tres versiones de la vida (49 funciones) y Una comedia española (39 funciones). La siguiente dramaturga es la británica Agatha Christie, con 176 funciones, con sus obras La ratonera (101 funciones) y Una visita inesperada (75 funciones). La tercera autora más representada es la estadounidense Eve Ensler con la obra Los monólogos de la vagina (173 funciones). Sigue la española Antonia San Juan con 156 funciones con los siguientes espectáculos: Hijos de su madre (63 funciones), La Terremoto de Alcorcón a precios populares (36 funciones), Las que faltaban (12 funciones) y Otras mujeres (45 funciones). Y la quinta dramaturga más representada es la española Ana Diosdado con la obra Olvida los tambores (131 funciones). 
Si nos fijamos solo en las obras más representadas, nuestra lista sufre unos cambios, como podemos ver en la tabla siguiente:

\begin{tabular}{|l|l|l|l|}
\hline Espectáculo & Autora & $\begin{array}{l}\text { Números de } \\
\text { funciones }\end{array}$ & País \\
\hline $\begin{array}{l}\text { Los monólogos de la } \\
\text { vagina }\end{array}$ & Eve Ensler & 173 & Nueva York (Estados Unidos) \\
\hline Olvida los tambores & Ana Diosdado & 131 & España (Europa) \\
\hline Arte & Yasmina Reza & 112 & Francia (Europa) \\
\hline La ratonera & Agatha Christie & 101 & Inglaterra (Europa) \\
\hline La calumnia & Lillian Hellman & 76 & Nueva Orleans (Estados Unidos) \\
\hline
\end{tabular}

\section{Tabla 2}

La dramaturga que encabeza la lista es Eve Ensler, seguida por Ana Diosdado, Yasmina Reza, Agatha Christie y la estadounidense Lillian Hellmann con La calumnia (76 funciones).

A través del análisis de las obras representadas en estos años asistimos a la presencia de autoras distintas que reflejan el período en el que viven: si antes la mujer intentaba reconocerse en un panorama de escritores de sexo masculino, ahora conquista su independencia. De hecho, la mayoría de las autoras analizadas ha estudiado teatro, dirige obras e imparte clases de dramaturgia en distintos Centros y Universidades.

Además, los temas tratados por todas las dramaturgas son diversos, ya que, analizando las obras representadas, podemos distinguir seis temas principales: el feminismo, el de las relaciones sociales, el histórico, el policíaco, el político y el religioso.

El tema del feminismo es el más representado con 25 obras. De hecho, las dramaturgas hablan de este tema en distintas facetas como la autoafirmación de la identidad femenina, la violencia de género, la maternidad, el acoso escolar, las diferencias sexuales. A través de estas obras, las dramaturgas denuncian los abusos sobre la mujer, que defiende sus derechos 
contra las imposiciones de la sociedad: pensemos por ejemplo en Mi vida gira alrededor de 500 metros de Inmaculada Alvear o en Pared de Itziar Pascual, obras en las que se habla de las mujeres que han muerto no solo por la violencia sino también por la indiferencia de la realidad contemporánea.

Las dramaturgas que en cambio centran sus obras en la descripción de la sociedad son muchas: gracias a 21 obras, asistimos a una fuerte crítica del mundo que nos rodea, caracterizado por diferencias sociales (La pecera de Yolanda Dorado), problemas económicos (Caídos del cielo de Paloma Pedrero), reivindicaciones de paternidad (El día del padre de Ana Graciani), el suicidio (4.48 Psicosis de Sarah Kane), etcétera.

En 13 obras encontramos el tema histórico, no solo relacionado con la guerra civil española (Los niños perdidos de Laila Ripoll), sino también con las guerras mundiales (Conversación con Primo Levi de Mercedes Lezcano), con el golpe de estado en Argentina (Contracciones de Marta Betoldi) y con las guerras imperialistas del siglo XX (En pie de guerra de Marisol Aznar).

La obra Superficie: vestimos a la humanidad de Pilar Almansa, Mónica Sagrera y Lourdes León se adscribe tanto al tema político como al tema social, dado que, a través del paralelismo entre los regímenes totalitarios y los grandes almacenes, las autoras hacen una crítica despiadada de una sociedad donde la imperfección y la diversidad no tienen cabida.

Encontramos el tema religioso en el Auto de los Reyes Magos y en el Misterio del Cristo de los Gascones de Ana Zamora, dramaturga que ha tenido el mérito de acercar el teatro del siglo XIII al mundo contemporáneo, a través de ropajes, instrumentos musicales antiguos y textos que mezclan la lengua vernácula al latín.

Las únicas dos obras que se adscriben al género policiaco pertenecen a Agatha Christie: La ratonera y Una visita inesperada son los textos más conocidos de la dramaturga británica que, por su obra amplia y variada, ha dejado una importante huella en el género policial. De hecho, sus obras siguen siendo las más representadas a nivel internacional.

Para concluir, podemos afirmar que las dramaturgas de estos anos abordan muchísimos temas y lo hacen a través de una nueva visión 
del mundo, debida a las diferencias, en ciertos aspectos, entre hombres y mujeres: "Si el arte es un acto expresivo, y todo acto expresivo por su origen es subjetivo, parece evidente que las expresiones dramáticas femeninas estarán connotadas por las vivencias externas e interiores de las autoras, que son distintas de las masculinas" (Serrano, 2005: 96).

Gracias a estas nuevas visiones femeninas, el teatro goza de valiosas aportaciones que enriquecen el panorama español contemporáneo y que dan muestra de una serie de preocupaciones personales y sociales de gran actualidad.

\section{REFERENCIAS BIBLIOGRÁFICAS}

ANÓNIMO (2008). "Segunda vida, de Aitana Galán: Una obra de teatro basada en Second Life". 18 de abril, 8. En http://interactivadigital. com/segunda-vida-de-aitana-galan [28/12/2017].

BESÓ PORTALÉS, C. (2008). "El teatro de Agatha Christie en la posguerra española”. Tonos. Revista Electrónica de Estudios Filológicos XV (también en http://www.um.es/tonosdigital/znum15/secciones/ estudios-6-AgathaChristie.htm [30/12/2017]).

BONACCORSI, A. D. (2016). Cartelera teatral en "ABC de Madrid” (19801984). Tesis de doctorado, dirigida por José Romera Castillo. Inédita hasta el momento en formato impreso, aunque puede leerse en la web delCentro: http://www2.uned.es/centro-investigacion-SELITEN@T/ pdf/Tesis_Cartelera_teatral_ABC_Madrid_1980-1984.pdf [30/12/2017].

(2017). "Puestas en escena de obras de dramaturgas en la cartelera de ABC de Madrid (1980-1984)". Signa. Revista de la Asociación Española de Semiótica 26, 43-66 (también en http://revistas.uned.es/ index.php/signa/article/view/19948/16628 [28/12/2017]). 
CÁCERES RUIZ, C. (2011). "Reseña crítica de la obra teatral Night mother de Marsha Norman". Crítica. Revista Latinoamericana de ensayo $\mathrm{XX}, 16$ de agosto, 11 (también en http://critica.cl/teatro/resenacritica-de-la-obra-teatral-"night-mother"-de-marsha-norman ?pr int $=p d f[30 / 12 / 2017])$.

CASADO VEGAS, A. y NIETO YUSTA, O. (2017). "Sobre puestas en escena de teatro lésbico (2000-2017)". En Teatro y marginalismo(s) por sexo, raza e ideología en los inicios del siglo XXI, José Romera Castillo (ed.), 193-225. Madrid: Editorial Verbum.

CRUZ, J. (2006). "Mercedes Lezcano defiende sus Conversaciones con Primo Levi”. El País, 11 de febrero, 6 (también en https://elpais. com/diario/2006/02/11/espectaculos/113961240 1_850215.html [29/12/2017]).

DÍAZ SANDE, J. R. (2006). "Mi vida gira alrededor de 500 metros. Entrevista". En http:// www.madridteatro.eu/teatr/entrevistas/2007/ entrevista174.htm [29/12/2017].

FERNÁNDEZ MORALES, M. (2006). "Lenguaje, género y espacios de poder. Puesta en escena del discurso médico en Wit de Margaret Edson”. En Mujeres, espacios y poder, Mercedes Arriaga Flórez (ed.), 266-275. Sevilla: Arcibel Editores.

GARNIER, E. (2004). "Pared, la escritura medianera". Primer Acto. Cuadernos de Investigación Teatral 306, 21-27.

GUERRERO DEL RÍO, E. (2005). "Narciso de Manuela Infante: la obra de unos jóvenes con futuro". La Tercera, 14 de agosto, 5.

LO PORTO, V. (2012). "Puestas en escena de obras de dramaturgas en la cartelera de ABC de Madrid (1990)". Signa. Revista de la Asociación Española de Semiótica 21, 369-393 (también en http://www. cervantesvirtual.com/obra/puestas-en-escena-de-obras-de-drama tur gas-en la-cartelera-de-abc-de-madrid-1990/ [29/12/2017]). (2013). Cartelera teatral en "ABC de Madrid” (1990-1994). Tesis de doctorado, dirigida por José Romera Castillo. Inédita, aunque puede leerse en http://www.uned.es/centroinvesti gacion-SELITEN@T/pdf/ 
ValeriaLoPorto.pdf [30/12/2017].

LÓPEZ ESCUER, A. (2017). "Pilar G. Almansa: El teatro es un secreto en sí mismo". 7 de noviembre, 17. En http://www.cooperadores-bilbao. com/web/?p=20551 [29/12/2017].

PÉREZ-RASILLA, E. (2007). "Perro muerto en tintorería: los fuertes, violencia contra la violencia". En http://www.madridteatro.eu/teatr/ teatro/2007/teatro313.htm [30/12/2017].

PRIETO NADAL, A. (2015). El teatro de Lluïsa Cunillé en el siglo XXI (2000-2014). Tesis de doctorado, dirigida por José Romera Castillo, que puede leerse en http://www2.uned.es/centro-investigacionSELITEN@T/pdf/Ana_Prieto_Nadal.pdf[03/01/2018].

ROMERA CASTILLO, J. (2010). "Estudio de las dramaturgas en los Seminarios Internacionales del SELITEN@T y en la revista Signa. Una guía bibliográfica". En Teatrología. Nuevas perspectivas. Homenaje a Juan Antonio Hormigón, M. F. Vieites y C. Rodríguez (eds.), 338-357. Ciudad Real: Naque.

(2011a). "Las dramaturgas y el SELITEN@T”. En su obra, Pautas para la investigación del teatro español y sus puestas en escena, 381411. Madrid: UNED (puede leerse en http://www2.uned.es/centroinvestigacion-SELITEN@T/pdf/EstudiosTeatro/7Dramaturgas siglos XXXXI.pdf [29/12/2017]).

(2011b). "Las dramaturgas". En su obra, Teatro español entre dos siglos a examen, 318-320. Madrid: Verbum.

(2014). "Algo más sobre dramaturgias femeninas en los inicios del siglo XXI". En Del gran teatro del mundo al mundo del teatro. Homenaje a la profesora Urszula Aszyk, Karolina Kumor y Katarzyna Moszczynska-Dürst (eds.), 245-255. Varsovia: Instituto de Estudios Ibéricos e Iberoamericanos de la Universidad de Varsovia. (2016). "Dramaturgas argentinas estudiadas en el SELITEN@T". En Hispanismos del mundo. Diálogos y debates en (y desde) el Sur (Actas del XVIII Congreso de la Asociación Internacional de Hispanistas), Leonardo Funes (ed.), sección V, 457-466. Buenos 
Aires: Miño y Dávila Editores (que puede leerse en $h t t p: / / w w w 2$. uned.es/centro-investigacion-SELITEN@T/pdf/Buenos_Aires_ ramaturgas_argentinas.pdf [03/01/2018]).

SÁNCHEZ MARTÍNEZ, S. (2005). Aspectos semiológicos en la dramaturgia de Paloma Pedrero. Tesis de doctorado defendida en la UNED. Inédita, aunque puede leerse en http://www2.uned.es/centroinvestigacion-SELITEN@T/pdf/SoniaSanchez.pdf [03/01/2018].

VALLEJO, J. (2005). "Romance de presas". El País, 29 de octubre, 05, (también en https://elpais.com/diario/2005/10/29/ babelia/1130540780_850215.html [28/12/2017]).

(2007). "La zarzuela, mejor que Wagner". El País, 8 de septiembre, 7 (también en https://elpais.com/diario/2007/09/08/ babelia/1189206373_850215.html[29/12/2017]).

VIDAL EGEA, A. (2010). El teatro de Angélica Liddell (1988-2000). Tesis de doctorado defendida en la UNED. Inédita en formato impreso, aunque puede leerse en http://www2.uned.es/centro-investigacionSELITEN@T/pdf/TESIS_ANA_VIDAL_SOBRE__ LIDDELL.pdf [03/01/2018].

VIOLA, A. (2012a). "Puestas en escena de obras de dramaturgas en la cartelera de $A B C$ de Madrid (2000)". Signa. Revista de la Asociación Española de Semiótica 21, 395-415 (también en http://descargas.cervantesvirtual.com/servlet/SirveObr as/04702707659336506317857/047380.pdf?incr=1 [30/12/2017]). (2012b). Cartelera teatral en "ABC de Madrid" (2000-2004). Tesis de doctorado, dirigida por José Romera Castillo. Inédita en formato impreso, disponible en: http://www.uned.es/centro-investigacionSELITEN@T/pdf/AnitaViola.pdf [29/12/2017].

Recibido el 24 de enero de 2018.

Aceptado el 13 de mayo de 2018. 
